\title{
Study on Income Allocation of Overseas Warehouse Alliance which Based on Shapley Value
}

\author{
Yuying Liu ${ }^{1,2, *}$ \\ ${ }^{1}$ College of Economics and Management, Lanzhou Institute of Technology, Gansu, China \\ ${ }^{2}$ Provincial Key Laboratory of E-commerce Operations, Lanzhou 730050, China \\ liuyuying126@163.com
}

Keywords: Overseas warehouse alliance; Shapley value; Revenue distribution

Abstract: The overseas warehouse alliance is a significant innovation of logistics mode in cross-border e-commerce. The mechanism of revenue distribution is scientific and reasonable which guarantees the stable operation of the overseas warehouse alliances. Shapley value method has some disadvantages of revenue distribution for the overseas warehouse alliance, These deficiencies can be properly modified by introducing the personalized service factors, so that the overall profit of the alliance is optimized.

\section{Introduction}

With the rapid development of cross-border e-commerce, overseas warehouses have become the fastest-growing cross-border logistics in recent years. Overseas warehouse is a form of cross-border logistics that can achieve local sales through the bulk export of goods to overseas warehouses and local delivery. This new logistics model of cross-border e-commerce effectively improves the efficiency of logistics delivery and reduces the delivery time.it can also easily achieves the package tracking and return, and greatly reduces the barriers to entry and probability of damage and loss. Overseas warehouses can solve many problems which exist in cross-border logistics, and moreover bring a good shopping experience for customers. YiCang Science and Technology Co., Ltd has researched for more than 200 cross-border sellers who use overseas warehouses. Due to the need of individualized service, the dissatisfaction of the third party service and the reduction of the overall cost, the overseas sellers will choose to build overseas warehouses by themselves. Survey results show that $17 \%$ of the sellers have established overseas warehouse or overseas branch, $38 \%$ of the sellers said that they are planning, more than $68 \%$ of the sellers are optimistic about huddle. Because of the broad prospects of overseas warehouse, the demand for overseas warehouse which continued to grow. The blind expansion caused the good and bad of overseas warehouse at the same time. Many overseas warehouses have problems such as lack of functions, high vacancy rates, low prices to grab the market and low efficiency (Fang Ji, 2015). The single overseas warehouse, which has short board in terms of capital and resources, is difficult to eliminate its existing drawbacks and to get out of the development dilemma. A new cross-border logistics model that is to say the overseas warehouse alliance, driven by the profit-making mechanism has emerged. 


\section{The cause of overseas warehouse alliance}

In fact, the overseas warehouse alliance is a cooperative game between independent overseas warehouse enterprises with contractual relationship. Many members of the overseas warehouse alliance are independent enterprises with overseas warehouse. These independence enterprises will establish a resource-sharing business alliance. The different contractual entities within the Union all over the world jointly carry out warehousing and other services through the establishment of logistics service platform, and integrate into a unified warehousing network.

So that cross-border e - commerce orders can achieve the global inventory sharing and circulation, and realize the balance of benefit-sharing according to the mode of shared interest.

The overseas warehouse member companies complement each other and risk sharing, thereby improving the efficiency of resource allocation to deal with the rapidly changing environment. The overseas warehouse alliance can set up the two-way supply channel of import and export through the platform, excavate the data of the warehouse platform from the aspects of process, intelligence, visualization. These data can provide cross-border sellers with warehousing and distribution services which are fast, accurate, diversified and customized. The overseas warehouse alliance can give sellers the necessary services, such as overseas processing, on-demand assembly and others services, it will move toward the direction of integrated operation.

The effective overseas alliance will not only alleviate the vicious competition between single overseas warehouses and promote the upgrading of overseas warehouses, but also enhance the overall competitive advantage of the alliance. Through the effective integration and efficient utilization of cross-border logistics resources, the stronger the Matthew effect will be finally realized. The overseas warehouse alliance, which aims to reduce capital investment through economies of scale, flexibly copes with fluctuations in demand and reduce costs, , has aroused widespread concern. In 2016, the Overseas Warehouse Alliance, which was launched by Chen Xianting of the Qianhai Quartet, was formally established. At present, the overseas warehouse within this Union owns 81 overseas warehouses in over 17 countries, covering 42 independent enterprises (Yueting Chai, 2016) .The overseas warehouse number in Europe and the United States accounted for nearly $60 \%$ of the total number of overseas positions. The overseas warehouse alliance is like mushrooming flourish, it broke the original mutual fight, and the alliance to share the overseas warehouse market, such as FTZCOC cross-border e-commerce public overseas warehouse, Globalfulfill global overseas warehouse alliance has been formally launched operations.

\section{The importance of income distribution of overseas warehouse alliance}

The overseas warehouse alliance is driven by the interest mechanism. The fair and reasonable income distribution is the prerequisite for the formation of the overseas warehouse alliance, and also the key factor to maintain the stability of the alliance. The overseas warehouse alliance is actually a behavior of cooperative game. The overseas warehouse alliance can obtain the sum of the profits that exceed the individual operating income of the member enterprises through cooperation, but at the same time, all the overseas warehouse enterprises participating in joining are still independent interest individual. the rational principle of the individual also determines that each enterprise will pursue their own interests to maximize (Myerson, R.B,2001). How to coordinate the interests of all parties in such a relationship of cooperative and competitive is an important guarantee for the existence and development of overseas alliance. The reasonable profit distribution scheme can form a "positive incentive" to stimulate and attract more overseas warehouse enterprises to join in, so as to expand the overall "benefit cake" through further cooperation. On the contrary, it will lead to the breakdown of the cooperation of the enterprises that have joined. 


\section{Establishment of Income Allocation Model for Overseas Warehouse Alliance}

\subsection{The income distribution model of overseas warehouse alliance based on Shapley value} method

Shapley value method reflects the principle of distribution according to the size of contribution, which is used to solve the problem of income distribution in the case of multi-agent cooperative game. The algorithm reflects the distribution rule of multi-labor, and avoids the disadvantages of the average allocation. The existing independent overseas warehouse enterprise set $N=\{1,2, \ldots, n$,$\} , if$ for any subset $\mathrm{S}$ (representing any set of $\mathrm{n}$ enterprises) of $\mathrm{N}$ which corresponds to a characteristic function C (s) of alliance benefits.it is satisfies:

$$
\begin{gathered}
C(\phi)=0 \\
C(S 1 \cup S 2) \geq C(S 1)+C(S 2), S 1 \cap S 2=\phi, S 1, S 2 \subseteq I
\end{gathered}
$$

The above equation (1) shows that when a member firm i does not contribute to the cooperation among members of the alliance, it should not make any profit from the total cooperation gains. The formula (2) shows that all firms that have overseas franchisees can earn more than the sum of the returns of each enterprise doing business separately, otherwise, it is not necessary for each overseas warehouse enterprise to participate in the alliance (Zhanzhong Shi,2001).

There is a set $\varphi[C]=\left(\varphi_{1}[C], \varphi_{2}[C], \ldots, \varphi_{n}[C]\right)$,

Where $\varphi_{i}[C]$ represents the benefits that an i firm in an overseas warehouse union derives from the overall effectiveness of the alliance. The income distribution of an alliance satisfies the following formula:

$$
\begin{array}{r}
\sum_{i \in N} \varphi_{i}[C]=C(N) \\
\varphi_{i}(X+C)=\varphi_{i}(X)+\varphi_{i}(C)
\end{array}
$$

(3) shows that the overall revenue $\mathrm{C}[\mathrm{N}]$ generated by the overseas warehouse alliance is equal to the total income $\sum_{i \in N} \varphi_{i}[C]$ which comes from each enterprises that has joined overseas warehouse.Equation (3) reflects the rationality of the overall income.The revenue distributed to each independent overseas warehouse enterprises can be expressed as $\varphi_{i}[C]$ (Shapley value), which is the only.It can be expressed as:

$$
\varphi_{\mathbf{i}}[C]=\sum \gamma_{\mathrm{n}}(S)[C(S)-C(S-\{\mathbf{i}\})], \quad \forall \mathbf{i} \in N
$$

Among them, $[C(s)-C(s-\{\mathbf{i}\})]$ represents the marginal contribution of overseas franchisee $\mathrm{i} \in \mathrm{N}$ to affiliated cooperatives $\mathrm{S}, \quad \gamma_{n}(S)=\frac{(|S|-1) !(n-|S|) !}{n !}$ is the weighting factor of each overseas cooperatives $\mathrm{S},|\mathrm{S}|$ is the number of enterprises in the overseas cooperatives .

\subsection{The income distribution model of overseas warehouse alliance based on the modified Shapley value method}

The "geek camp" has conducted three rounds of surveys for different sellers. According to the survey, the primary reason for choosing a self-built overseas warehouse is to meet the needs of its own personalized service. In the first four factors, this primary factor accounted for $31 \%$ of the 
proportion. The Shapley value method is used to solve the problem of the income distribution of the overseas warehouse alliance, only according to the size of contribution to the distribution of income, but not the individual service cost incurred by the alliance enterprise in the process of warehousing and distribution(Xiaheng Zhang,2015).That is, The Shapley value method assumes that each franchisee in the overseas warehouse $N=\{1,2, \ldots, n\}$ has an equalized individual service cost factor, and it is $1 / n$, which is obviously an ideal condition.In order to rationalize the income distribution of the overseas warehouse alliance, it is necessary for us to make the necessary amendments to the above algorithm(Lee H, Padmanabhan P, Wang S,2003.). we need to reflect the personalized service of the overseas warehouse into the income distribution,so as to make it more in line with the actual operating conditions. $\Delta \mathrm{R}_{\mathrm{i}}$ represents the individualized service cost factor that the overseas warehouse Federation participating enterprises actually undertake in the implementation of warehouse operations, that is,It is the difference between $R_{i}$ and the individualized service cost for each party base on Shapley value method.The formula is expressed as $\Delta R_{i}=R_{i}-1 / n$, and $\sum_{i=1}^{n} R_{i}=1, \sum_{i=1}^{n} \Delta R_{i}=0$ 。According to the uncorrected Shapley value distribution method, we can see that the total benefit of the overseas warehouse alliance is $\mathrm{C}(\mathrm{N})$. $\Delta \eta_{i}(N)$ means the income adjustment amount which allocated by the overseas warehouse alliance enterprises from the increase of the income, That is $\Delta \eta_{i}(N)=C(N) \times \Delta R_{i} \cdot \eta_{i}(C)^{\prime}$ means that the allocation of the overseas warehouse alliance enterprises from the increased revenue,which is modified with the individualized service cost after the shapley value distribution scheme(TO $\mathrm{W}$ M,LAI L S L,2015). It can be expressed as $\eta_{i}(C)^{\prime}=\eta_{i}(C)+\Delta \eta_{i}(C)$.

When $\triangle R_{i} \geq 0$, $i$ that the overseas participants in the coalition have more personalized services in their cooperation. At this moment, the correction of its income distribution is greater than zero, that is, the participant $i$ can get more than before. on the contrary, When $\Delta R_{i} \leq 0$, Enterprise $i$ undertakes individualized service in the cooperation is relatively small. The correction amount of its income distribution is less than zero, that is, Less revenue can get than he correction(Xiangyang Li ,2014).

\section{Application of Shapley Model in Income Allocation of Overseas Warehouse Alliance}

Overseas Warehouse Alliance consists of an overseas warehouse company E1, E2, E3 together. If E1, E2, E3 operate independently, their costs were separately 180 ten thousand yuan,240ten thousand yuan,300 ten thousand yuan .E.g enterprise E1 and E2 union, E3 is alone, the cost is 540 ten thousand yuan.Such as enterprise E1, E3 Union, E2 alone operating, the cost is 550 ten thousand yuan.For example enterprise E2, E3 alliance and E1 single operation, the cost is 490 ten thousand yuan.Such as business E1, E2, E3 alliance,then the cost is 310 ten thousand yuan.The income distribution of E1, E2 and E3 of enterprises based on Shapley value method is calculated.

Table 1 Overseas warehouse alliance member company E1's income distribution. (unit:\$10,000)

\begin{tabular}{ccccc}
\hline $\mathrm{S}$ & $\left(\mathrm{E}_{1}\right)$ & $\left(\mathrm{E}_{1}, \mathrm{E}_{2}\right)$ & $\left(\mathrm{E}_{1}, \mathrm{E}_{3}\right)$ & $\left(\mathrm{E}_{1}, \mathrm{E}_{2}, \mathrm{E}_{3}\right)$ \\
\hline $\mathrm{C}(\mathrm{S})$ & 0 & 180 & 170 & 410 \\
\hline $\mathrm{C}\left(\mathrm{S}-\left\{\mathrm{E}_{1}\right\}\right)$ & 0 & 0 & 0 & 230 \\
\hline $\mathrm{C}(\mathrm{S})-\mathrm{C}\left(\mathrm{S}-\left\{\mathrm{E}_{1}\right\}\right)$ & 0 & 180 & 170 & 180 \\
\hline $\mathrm{S} \mid$ & 1 & 2 & 2 & 3 \\
\hline $\mathrm{W}(|\mathrm{S}|)$ & $1 / 3$ & $1 / 6$ & $1 / 6$ & $1 / 3$ \\
\hline $\mathrm{W}(|\mathrm{S}|)\left[\mathrm{C}(\mathrm{S})-\mathrm{C}\left(\mathrm{S}-\left\{\mathrm{E}_{1}\right\}\right)\right]$ & 0 & 30 & 28.33 & 60 \\
\hline
\end{tabular}

From table 1, we can calculate that the cost of member $E_{1}$ in overseas union is calculated as 
$\varphi_{\mathrm{E} 1}[C]=0+30+28.33+60=118.33$.

Similarly, the profit distribution of enterprise $\mathrm{B}$ and $\mathrm{C}$ respectively $\varphi_{\mathrm{E} 2}[C]=0+30+38.33+80=148.33, \varphi_{\mathrm{E} 3}[C]=0+28.33+38.33+76.67=144.33$.

When the business alone, Enterprises E1, E2, E3 need to pay the cost of 180 ten thousand yuan,240 ten thousand yuan,300 ten thousand yuan respectively.after joining the business, E1, E2, E3 need to pay the costs of 61.67 ten thousand yuan (180-118.33=61.67), 91.67 ten thousand yuan and 15.567 ten thousand yuan respectively.

Assuming that the individual service cost factors of the above three enterprises are: $\mathrm{R}_{\mathrm{E} 1}=0.3, \mathrm{R}_{\mathrm{E} 2}=0.5, \mathrm{R}_{\mathrm{E} 3}=0.2$. This can be calculated as follows $\Delta R_{E 1}=1 / 30, \Delta R_{E 2}=2 / 15$, $\Delta R_{E 3}=-1 / 6, \quad \mathrm{X}_{\mathrm{E} 1}^{\prime}(\mathrm{C})=132, \mathrm{X}_{\mathrm{E} 2}^{\prime}(\mathrm{C})=202, \mathrm{X}_{\mathrm{E} 3}^{\prime}(\mathrm{C})=76$.

Table 2 comparison of profit distribution schemes before and after improvement of Shapley value method. (unit:\$10,000)

\begin{tabular}{cccc}
\hline program & $\mathrm{E}_{1}$ & $\mathrm{E}_{2}$ & $\mathrm{E}_{3}$ \\
\hline Pre-correction program & 118.33 & 148.33 & 144.33 \\
\hline The revised program & 132 & 202 & 76 \\
\hline
\end{tabular}

\section{Conclusion}

Compared with the results before and after the shapley value improvement, we can see that the benefits gained by the enterprise E2 increase most and the benefits obtained by the enterprise E3 decrease .because the enterprise E2 provides the most personalized services and the E3 provides the least personalized service(Weihua Liu , Pan Zhao ,2007).In the income distribution, we should not only consider the contribution of alliance enterprises to the alliance, but also consider the influence of the main factor of personalized service on the income distribution, adhering to the principle of fairness and efficiency, so that the final distribution results tend to be more scientific and reasonable.

\section{References:}

[1] Yueting Chai, 2016. To make large-scale cross-border export market, these overseas warehouse companies actually allied .Billion state power network.www.ebrun.com/176338.shtml.

[2] Fang Ji, 2015.Cross-border e-commerce logistics model and its evolution, West Forum. (7), PP.102-107.

[3] Lee H, Padmanabhan P, Wang S, 2003.Information: distortion in a supply chain: the bullwhip effect, Management Seience.35 (26), pp.11-18.

[4] Xiangyang Li, 2014.Promote cross-border e-commerce logistics development path, China's Circulation Economy.15 (10), pp.107-112.

[5] Weihua Liu, Pan Zhao, 2007. Based on the shapley value method of supply chain alliance enterprises benefit distribution. Anhui Agricultural Sciences, 35 (26), pp. 13-21.

[6] Myerson, R.B, 2001. Game Theory, China Economic Publishing House. Beijing, 1nd edition.

[7] Zhanzhong Shi, 2001. Enterprise Strategic Alliance, Shanghai University of Finance and Economics Press. Shanghai, 1nd edition.

[8] TO W M,LAI L S L,2015. Data Analytics in China: Trends,Issues,and Challenges,IT Professional,17(4),pp.49 -55. [9] Xiaheng Zhang, 2015.China Cross-border E-commerce Logistics Dilemma and Countermeasures, Contemporary Economic Management.8 (5), pp.51-54. 